\title{
Are mean platelet volume and splenomegaly subclinical inflammatory marker in children with familial mediterranean fever?
}

\author{
Ismail Dursun ${ }^{1 *}$, Faysal Gok ${ }^{1}$, Oguzhan Babacan $^{2}$, Erkan Sarı $^{2}$, Onur Sakallıoglu, \\ Suleyman Kalman ${ }^{1}$, Ibrahim Gokce ${ }^{2}$ \\ ${ }^{1}$ Department of Pediatric Nephrology and Rheumatology, Gülhane Military Medical Academy, School of Medicine, Ankara, Turkey; \\ *Corresponding Author: drdursun@,hotmail.com \\ ${ }^{2}$ Department of Pediatrics, Gülhane Military Medical Academy, School of Medicine, Ankara, Turkey; faysalgok@yahoo.com, \\ gokcemd@yahoo.com
}

Received 6 February 2010; revised 2 Mrach 2010; accepted 5 March 2010.

\begin{abstract}
The present study aimed to investigate the correlation of MPV and splenomegaly as inflammation activity of FMF patients at the attacks free period. We retrospectively reviewed the medical records of $\mathbf{4 3}$ patients with FMF. This study was performed at the attack free period as clinical and laboratory. For this study, patients were divided into two groups. Patients with splenomegaly is called group $1(n=12)$ and patients with no splenomegaly is called group $2(n=31)$. Groups were compared respect to age, gender, platelet counts, acute phase reactants and MPV. The mean MPV (fl) were significantly higher in group $1(8.9 \pm 0.8)$ than in group $2(8.4 \pm 0.5, p<$ $0.05)$. This study suggested that increased MPV and splenomegaly without amyloidosis could be a sign of chronic inflammation in children with FMF even in attack free period.
\end{abstract}

Keywords: Familial Mediterranean Fever; Mean Platelet Volume; Subclinical Inflammation

\section{INTRODUCTION}

Familial Mediterranean fever (FMF) is a recessive disorder characterized by attacks of periodic fever and inflammation [1]. The FMF patients are asymptomatic, acute phase reactants (C-reactive protein, ESR) are nor$\mathrm{mal}$ in the attacs free period, but serum amyloid A (SAA) and some cytokines are constantly higher [2,3]. Subclinical inflammation continues in attack-free period in FMF patients $[3,4]$.

It has been reported that IL-6/HPRT is significantly higher than control in attack free period of FMF (3). IL-6 has been shown to promote megakaryocyte maturation in the absence of other growth factors. It possibly stimulates megakaryocyte proliferation. Administration of IL-6 has been shown to result in a significant increase in the platelet count [5]. Also it is a cytokine that can induce the formation of SAA and C-reactive protein (CRP) [6-8]. Erythrocyte sedimentation rate, CRP and SAA correlate closely with clinical disease activity in FMF patients [4].

The spleen acts as a reservoir for platelets; one-third of the circulating platelet mass is temporarily sequestered within a normal sized spleen, and up to 90 percent may be found within a markedly enlarged spleen. The etiology of splenomegaly may relate to an increase in a normal splenic process (e.g. hemolysis) or may be due to infiltrative, infectious, or vascular disorders [9]. Involvement of the reticuloendothelial system in FMF is rare mentioned in the literature $[10,11]$. Splenomegaly in patients with FMF may be related to the rate of platelet destruction. The changes of peripheral platelet volume depend on the rate of splenic sequestration and bone marrow production. The platelet survival is directly related to the lowest platelet count and inversely related to both the highest mean platelet volume and duration of the thrombocytopenia [12]. If the rate of platelet destruction is equal or higher than the rate of platelet production, mean platelet volume is increase because of increased peripheral immature platelets. If the rate of platelet destruction is lover than the rate of platelet production, mean platelet volume is normal or decrease $[12,13]$.

Mean platelet volume (MPV) is a parameter generated by full blood count analyzers as part of the routine complete blood count (CBC) test which is usually overlooked by clinicians. MPV correlates with the platelet 
function and activation. An association between FMF activity and MPV has not been investigated yet.

The present study aimed to investigate the correlation of MPV and splenomegaly as the inflammatory activity of FMF patients at the attacks free period.

\section{PATIENTS AND METHODS}

We retrospectively reviewed the medical records of 43 patients with FMF who were followed up in our Pediatric Nephrology and Rheumatology Unite. The diagnosis of FMF was made according to the diagnostic criteria which described by Livneh et al. and DNA analyses $[14,15]$. This study was performed at the attack free period. The attack free period was accepted if the clinically patient had no symptoms and in the laboratory, ESR and CRP were normal. Patients were divided into two groups according to splenomegaly. Patients with splenomegaly is called group $1(\mathrm{n}=12)$ and patients with no splenomegaly is called group $2(\mathrm{n}=31)$. Groups were compared respect to age, gender, platelet counts, acute phase reactants (ESR and CRP) and MPV. None of the patients had abnormal urinalysis for proteinuria. Splenomegaly has been established by physical examination and confirmed by abdominal ultrasound (USG). In USG examination, we used age and height dependant standarts for splenomegaly [16].

\section{STATISTICAL ANALYSIS}

All tests were performed using SPSS for Windows 15.0. The parameters with normal distribution were expressed as mean \pm SD and the parameters with abnormal distribution were expressed as median (minimum-maximum). Comparisons of means were performed with unpaired t-test. Comparisons of medians were performed with Mann-Whitney U-test. Comparisons of proportions were performed with Pearson-chi-squared test. A P value < 0.05 was accepted as statistically significant.

\section{RESULTS}

The results of genotype of the patients with FMF were showed in Table1. Table 2 shows epidemiological and laboratory findings of the patients with FMF. While the group 1 included two girls and ten boys, the group 2 included 15 girls and 16 boys. The mean age of the group 1 and group 2 were $11.0 \pm 4.4$ and $10.1 \pm 3.5$, respectively. The mean platelet counts of the group 1 and group 2 were $248500 \pm 67654$ and $281000 \pm 51847$, respectively. There was no significant difference between group 1 and group 2 according to age and platelet counts $(\mathrm{p}>0.05)$. The mean MPV (fl) were significantly higher
Table 1. Shows genotyping distribution of patients with FMF.

\begin{tabular}{lcc}
\hline MEF Mutation & Group1 $(\mathrm{n}=12)$ & Group 2 $(\mathrm{n}=31)$ \\
\hline M694V/M694V (n) & 5 & 8 \\
M694V/N (n) & 3 & 8 \\
M694V/V726A (n) & 1 & 2 \\
M694V/M680I (n) & 2 & 1 \\
V726A/R761H (n) & 1 & - \\
E148Q/N (n) & - & 3 \\
V726A/V726A (n) & - & 1 \\
M680I/V726A(n) & - & 1 \\
M694V/E148Q(n) & - & 2 \\
V726A/N(n) & - & 2 \\
Normal (n) & - & 3 \\
\hline
\end{tabular}

Table 2. Epidemiological and laboratory findings of the patients with FMF.

\begin{tabular}{|c|c|c|c|}
\hline Variables & $\begin{array}{l}\text { Patients with } \\
\text { splenomegaly } \\
\quad(\mathrm{n}=12)\end{array}$ & $\begin{array}{l}\text { Patients with no } \\
\text { splenomegaly } \\
(\mathbf{n}=31)\end{array}$ & $\mathbf{p}$ \\
\hline Age (years) ${ }^{*}$ & $11.0 \pm 4.4$ & $10.1 \pm 3.5$ & $>0.05$ \\
\hline Gender (M/F) & $10 / 2$ & $16 / 15$ & 0.05 \\
\hline $\begin{array}{l}\text { Platelets counts } \\
\left(\times 10^{3} / \mathbf{m m}^{3}\right)^{*}\end{array}$ & $248 \pm 68$ & $281 \pm 59$ & $>0.05$ \\
\hline $\begin{array}{l}\text { Mean platelet volume } \\
\text { (fl) })^{*}\end{array}$ & $8.9 \pm 0.8$ & $8.4 \pm 0.5$ & $<0.03$ \\
\hline
\end{tabular}

Mean \pm SD

in group $1(8.9 \pm 0.8)$ than in group $2(8.4 \pm 0.5, \mathrm{p}<0.05)$ (Table 2).

\section{DISCUSSION}

Involvement of the reticuloendothelial system in FMF is seldom mentioned in the literature [10,11]. Enlargement of the spleen without amyloid deposition has been reported in $30.7 \%$ of patients with FMF [17]. Aharoni et al. [18] detected splenomegaly in $27.5 \%, 13.3 \%$ of patients with FMF at the attack and at attack free period, respectively. In our study, splenomegaly was detected by physical examination and abdominal ultrasound in $27.9 \%$ of FMF patients at the attacks free period.

In literature, so far, it has not been reported study that investigates association between MPV and disease activity in patients with FMF. There are few studies about the association between MPV and the clinical activity of 
rheumatoid arthritis. Milovanovic et al. [19] have reported that in active disease IL-6 but not thrombopoietin (TPO) is related to platelet count. Thus, IL-6 raises platelet count in reactive thrombocytosis and the neutrophil count. In rheumatoid arthritis, MPV and myeloperoxidase also mirror the disease activity [19]. In the other study has been reported that cytokines and IL-6, IL-11 and growth factors (e.g. TPO) may also contribute to the pathologic megakaryocytopoiesis of RA [20]. Kisacik et al. [21] have been shown the correlation between MPV and the clinical activity of rheumatoid arthritis and ankylosing spondylitis. They suggest the assessment of MPV that may provide additional information about inflammation in AS and RA.

Up now, there are two study that has been shown the association with splenomegaly and genotype in patients with FMF in the literature [22,23]. Kone et al. [22] showed that homozygosity for the M694V mutation correlated with splenomegaly. But, Inal et al. [23] didn't detect the association with splenomegaly and genotype in patients with FMF. In our study, since the the number of the patients is small to do the correlation with the genotype and splenomegaly, we do not find the result statistically significant.

In conclusion, the diagnosis of FMF is based mainly on the clinical criteria and laboratory examinations. We found the correlation of MPV and splenomegaly as the inflammatory activity of FMF patients at the attacks free period. These could help to diagnosis of the FMF and may be applible for clinical chronic inflammatory condition score marker that related to prognosis or the possibility that development of amiloidosis. Further and including much more number patients studies are needed to confirm.

\section{REFERENCES}

[1] Woo, P., Laxer, R.M. and Sherry, D.D. (2007) Autoinflammatory syndromes. In: Woo, P., Laxer, R.M. and Sherry, D.D. Eds., Pediatric Rheumatology in Clinical Practice, Springer, London, 123-136.

[2] Direskeneli, H., Ozdogan, H., Korkmaz, C., Akoglu, T. and Yazici, H. (1999) Serum soluble intercellular adhesion molecule- 1 and interleukin- 8 levels in familial Mediterranean fever. The Journal of Rheumatology, 26(9), 1983-1986.

[3] Notarnicola, C., Didelot, M.N., Seguret, F., Demaille, J. and Touitou, I. (2002) Enhanced cytokine mRNA levels in attack-free patients with familial Mediterranean fever. Genes \& Immunity, 3(1), 43-45.

[4] Yalcınkaya, F., Cakar, N., Acar, B., Tutar, E., Güriz, H., Elhan, A.H., et al. (2007) The value of the levels of acute phase reactants for the prediction of familial Mediterranean fever associated amyloidosis: A case control study. Rheumatology International, 27(6), 517-522.
[5] Kerr, R., Stirling, D. and Ludlam, C.A. (2001) Interleukin 6 and haemostasis. British Journal of Haematology, 115(1), 3-12.

[6] Manukyan, G.P., Ghazaryan, K.A., Ktsoyan, Z.H.A., Tatyan, M.V., Khachatryan, Z.A., Hakobyan, G.S., et al. (2008) Cytokine profile of Armenian patients with Familial Mediterranean fever. Clinical Biochemistry, 41 (10-11), 920-922.

[7] Akcan, Y., Bayraktar, Y., Arslan, S., Van Thiel, D.H., Zerrin B.C. and Yildiz, O. (2003) The importance of serial measurements of cytokine levels for the evaluation of their role in pathogenesis in familial Mediterraean fever. European Journal of Medical Research, 8, 304-306.

[8] Baykal, Y., Saglam, K., Yilmaz, M.I., Taslipinar, A., Akinci, S.B. and Inal, A (2003) Serum sIL-2r, IL-6, IL-10 and TNF-alpha level in familial Mediterranean fever patients. Clinical Rheumatology, 22(2), 99-101.

[9] Heath, H.W. and Pearson, H.A. (1989) Thrombocytosis in pediatric outpatients. Journal of Pediatrics, 114(5), 805-807.

[10] Rimon, D., Meir, Y. and Cohen, L. (1989) Retroperitoneal lymphadenopathy in familial Mediterranian fever. Postgraduate Medical Journal, 65(768), 776-778.

[11] Schwabe, A.D. and Peters, R.S. (1974) Familial Mediterranean fever in Armenians. Analysis of 100 cases. Medicine, 53(6), 453-462.

[12] Castle, V., Coates, G., Kelton, J.G. and Andrew, M. (1987) 111 in-oxine platelet survivals in thrombocytopenic infants. Blood, 70(3), 652-656.

[13] Savolainen, S. (1992). SPECT versus planar scintigraphy for quantification of splenic sequestration of 111 in-labelled platelets. Nuclear Medicine Communications, 13 (10), 757-763.

[14] Livneh, A., Langevitz, P., Zemer, D., Kees, S. and Lidav, T. (1997) Criteria for the diagnosis of familial Mediterranean fever. Arthritis \& Rheumatism, 40(10), 18791885.

[15] Duşunsel, R., Dursun, I., Gündüz, Z., Poyrazoğlu, M.H., Gürgöze, M.K. and Dundar, M. (2008) Genotype-phenotype correlation in children with familial Mediterranean fever in a Turkish population. Pediatrics International, 50(2), 208-212.

[16] Konuş, O.L., Ozdemir, A., Akkaya, A., Erbaş, G., Celik, H. and Işik, S. (1998) Normal liver, spleen, and kidney dimensions in neonates, infants, and children: Evaluation with sonography. American Journal of Roentgenology, 171(6), 1693-1698.

[17] Aharoni, D., Hiller, N. and Hadas H.I. (2000) Familial Mediterranean fever: Abdominal imaging findings in 139 patients and review of the literature. Abdom Imaging, 25(3), 297-300.

[18] Odabas, A.R., Cetinkaya, R., Selcuk, Y. and Bilen, H. (2002) Familial Mediterranean fever. Southern Medical Journal, 95(12), 1400-1403.

[19] Milovanovic, M., Nilsson, E. and Järemo, P. (2004) Relationships between platelets and inflammatory markers in rheumatoid arthritis. Clinica Chimica Acta, 343(1-2), 237-240.

[20] Ertenli, I., Kiraz, S., Oztürk, M.A., Haznedaroğlu, I., Celik, I. and Calgüneri, M. (2003) Pathologic thrombopoiesis of rheumatoid arthritis. Rheumatology International, 23(2), 49-60. 
[21] Kisacik, B., Tufan, A., Kalyoncu, U., Karadag, O., Akdogan, A., Ozturk, M.A., et al. (2008) Mean platelet volume (MPV) as an inflammatory marker in ankylosing spondylitis and rheumatoid arthritis. Joint Bone Spine, 75(3), 291-294.

[22] Koné, P.I., Dubuc, M., Sportouch, J., Minodier, P., Garnier, J.M. and Touitou, I. (2000) Phenotype-genotype correlation in 91 patients with familial Mediterranean fever reveals a high frequency of cutaneomucous features. Rheumatology, Oxford, 39(11), 1275-1279.

[23] Inal, A., Yilmaz, M., Kendirli, S.G., Altintas, D.U. and Karakoc, G.B. (2008) The clinical and genetical features of 124 children with Familial Mediterranean fever: Experience of a single tertiary center. Rheumatology International, 29(11), 1279-1285. 